\title{
Cognitive errors assessed by observer ratings in bipolar affective disorder: relationship with symptoms and therapeutic alliance
}

\author{
Ueli Kramer $^{1 *}$, Guy Bodenmann ${ }^{2}$ and Martin Drapeau ${ }^{3}$ \\ ${ }^{1}$ Department of Psychology and Department of Psychiatry - CHUV, University of Lausanne, Switzerland \\ ${ }^{2}$ McGill University, Montréal, Canada \\ ${ }^{3}$ University of Fribourg, Switzerland
}

Received 26 January 2009; Accepted 14 May 2009; First published online 4 June 2009

\begin{abstract}
The construct of cognitive errors is clinically relevant for cognitive therapy of mood disorders. Beck's universality hypothesis postulates the relevance of negative cognitions in all subtypes of mood disorders, as well as positive cognitions for manic states. This hypothesis has rarely been empirically addressed for patients presenting bipolar affective disorder (BD). In-patients $(n=30)$ presenting with BD were interviewed, as were 30 participants of a matched control group. Valid and reliable observer-rater methodology for cognitive errors was applied to the session transcripts. Overall, patients make more cognitive errors than controls. When manic and depressive patients were compared, parts of the universality hypothesis were confirmed. Manic symptoms are related to positive and negative cognitive errors. These results are discussed with regard to the main assumptions of the cognitive model for depression; thus adding an argument for extending it to the BD diagnostic group, taking into consideration specificities in terms of cognitive errors. Clinical implications for cognitive therapy of $\mathrm{BD}$ are suggested.
\end{abstract}

Key words: Bipolar affective disorder, cognitive errors, cognitive therapy, observerrater method.

\section{Introduction}

Introduced in 1963 by A. T. Beck, the concept of cognitive errors (or cognitive distortion) has become one of the central features of cognitive theory and therapy for depression (Beck, 1995; Clark et al. 1999); later, cognitive research used the term of cognitive biases, a term that is currently in use mostly for experimentally based studies (Clark et al. 1999); in accordance with Beck, we will refer to the term cognitive errors (CE). Beck (1963) observes that the main suffering in depressive patients is not caused by affective disturbances, but by pervasiveness of inaccuracy in interpreting reality - errors in logic - in such a way that the result is a

\footnotetext{
* Author for correspondence: Dr U. Kramer, Institute for Psychotherapy, Department of Psychiatry - CHUV, Site de Cery, CH-1008 Prilly-Lausannne, Switzerland. (email: Ueli.Kramer@chuv.ch)

C 2009 British Association for Behavioural and Cognitive Psychotherapies
} 
generalized negative bias against themselves; this assumption is called 'negativity hypothesis' (see also Peterson \& Seligman, 1984; Beck, 1991). According to the constructivist cognitive theory (Beck, 1991; Clark et al. 1999), normal thinking does not mean complete accuracy with reality, the latter always being an individual's construction, but an 'adaptive' way of information processing. Normal cognitive functioning is therefore characterized by a slightly positive bias which, when the individual shifts into depressive mood, fades away and is replaced by a negative bias. Along with a series of other hypotheses, Beck $(1967,1976$, 1991; Clark et al. 1999) defines the 'universality hypothesis' as follows: 'Heightened negative cognition, reduced positive thinking, and self-referent negativity processing bias are evident in all subtypes of depression' (Clark et al. 1999, p. 159). With more detail for bipolar affective disorders (BD), Beck (1991) postulates overly positive biases in individuals in manic episodes and overly negative biases when they are in depressive episodes (see also Newman et al. 2001; Leahy, 2003). More recently, Mansell et al. (2007) developed an integrative cognitive model for the explanation of mood swings in BD. The multi-factor model implies at least three levels, i.e. change in internal state, appraisals and belief about self, the world and others, on which cognitive biases, or CE may apply, underlying the omnipresence of the latter. Thus, the present study aims at testing part of Beck's universality hypothesis, by focusing on CE in BD. Empirical evidence on this hypothesis will be reviewed and methodological issues related to the assessment of cognitive processes discussed, before addressing our specific research questions related to BD.

Results from previous empirical work on CE confirmed Beck's hypotheses for patients presenting unipolar depression (Clark et al. 1999). Depressed persons showed more CE than non-depressed (Hammen \& Krantz, 1976; Hammen, 1978; Krantz \& Hammen, 1979). More specifically, the category of selective abstraction yielded a particularly large between-group difference, greater than for the category of personalization. For patients presenting lower back pain with comorbid depression, overgeneralization was most often reported, compared to all other errors (Lefebvre, 1981). However, the author acknowledged that the latter result may possibly be induced by the formulation of the questionnaire, which focused on contents related to lower back pain. As shown by Weintraub et al. (1974), CE were persistent across phases of unipolar depression and remission, and functioned thus as a vulnerability factor in relapse in depression-prone individuals. This effect was not found consistently (Haaga et al. 1991). An experimental mood-induction study on non-depressed subjects was conducted by Henriques \& Leitenberg (2002), who found that the ratio of negative-to-positive CE predicted best the outcome variables (e.g. self-esteem, mood change). Even if these studies tend to confirm Beck's assumptions and more generally the cognitive model of unipolar depression, it is doubtful that the results of such laboratory studies, i.e. using questionnaires, are directly applicable to clinical contexts, such as enhancement of the cognitive case conceptualization and the psychotherapeutic intervention (see below).

With regard to patients presenting with BD I or BD II, there is some tentative evidence that Beck's universality hypothesis concerning the presence of negative cognition across all subtypes of depression, holds true (Clark et al. 1999). Weingartner et al. (1977) conduct a word-encoding study on eight BD patients and showed that the recall was better in the case of mood congruency, compared to mood incongruency. Eich et al. (1997) were unable to reproduce the congruency effect on word recall ( $n=10 \mathrm{BD}$ rapid cyclers), but reproduced it on autobiographical events. Cognitive coping specificities and dysfunctional attitudes in BD have been addressed by a number of empirical studies (e.g. Greenhouse et al. 2000; Lam et al. 
2001, 2004; Johnson \& Carver, 2006; Kramer et al. 2009). Recently, a questionnaire was devised aimed at assessing hypomanic cognitions (Mansell \& Jones, 2006; see also Jones et al. 2006), which succeeded in differentiating BD patients from controls: the former presented higher scores on cognitions related to hypomania, compared to the latter. Goldberg et al. (2008) showed in a recent questionnaire study that core beliefs in BD patients remain negativistic even during manic phases. These authors interpreted this pattern as possible cognitive overcompensation of the depressive phase. Based on these studies, Mansell et al. (2007) developed an integrative cognitive model of understanding BD. The model postulates the presence of intense conflicting appraisals of change in the internal states, which may be both positive and negative during the manic phase. Based on these studies and conceptual elaborations, it can be concluded that there may be specific cognitive patterns in BD patients in terms of cognitive biases, mainly negative biases in the depressive phase and both negative and positive biases in the manic phase of the disorder.

Assessment of cognitive biases or errors has traditionally been done by means of self-report measures (e.g. Lefebvre, 1981; Goldberg et al. 2008); these methods might be useful in some contexts, on condition that the individual is aware of his or her own errors in cognitive processing (other limitations of self-report measures are social desirability, tendency for acquiescing and self-deception). In highly disturbed psychiatry patients, this is rarely the case. This has led recent researchers to devise standardized experimental testing procedures (for depression see Jermann et al. 2005). These tests, inspired by neuropsychological research paradigms, might be useful for testing a specific hypothesis in fundamental research, but suffer from a lack of external and ecological validity and are therefore of limited direct relevance for psychotherapeutic practice, and also because they are based on aggregated datasets. Other limitations of the application of neuropsychological research to psychotherapy practice are outlined by Eells et al. (1993) and Clark et al. (1999). Finally, the CE Rating Scale (Drapeau et al. 2005) was devised in order to compensate for the shortcomings of the two previously mentioned research paradigms, i.e. self-reports and neuropsychological tests, and to offer valid conceptualization of CE by using observer ratings of CE, based on transcripts of psychotherapy sessions (see Method section).

Taking Beck's negativity and universality hypotheses as a basis, we are in the position of formulating the following research hypotheses: (1) BD patients display more CE, in total and per category, than controls; (2) patients with predominantly manic symptoms display positive and negative $\mathrm{CE}$, patients with predominantly depressive symptoms display more negative $\mathrm{CE}$; (3) a higher proportion of CE in patients is associated with higher symptom level; (4) a higher proportion of $\mathrm{CE}$ in patients is associated with lower levels of therapeutic alliance.

\section{Method}

\section{Sample}

A total of 30 in-patients with BD were included in the study, of which 20 (67\%) were female; the patients had a mean age of 46.1 years (S.D. $=11.2$, range 21-60). Their socio-demographic level was assessed by means of the total number of years of education in any field. On average, the patients had 12.4 years of education (S.D. = 1.1, range 10-16). All had a DSM-IV-R diagnosis of BD I and were included in the study irrespective of the nature of the most recent phase or of the level of chronicity. Some $(n=13,43 \%)$ presented comorbid disorders, 
Table 1. Socio-demographics and symptoms for patients and controls

\begin{tabular}{|c|c|c|c|c|c|c|}
\hline \multirow[b]{2}{*}{ Criteria } & \multicolumn{2}{|c|}{ Patients $(n=30)$} & \multicolumn{2}{|c|}{ Controls $(n=30)$} & \multirow[b]{2}{*}{$t(1,58)$} & \multirow[b]{2}{*}{$p$} \\
\hline & Mean & S.D. & Mean & S.D. & & \\
\hline Age & 46.14 & 11.20 & 41.90 & 14.33 & 1.28 & 0.12 \\
\hline Education (no. of years) & 12.37 & 1.07 & 12.87 & 1.42 & -1.59 & 0.21 \\
\hline Gender (female) & $67 \%$ & & $67 \%$ & & & \\
\hline Intimate relationship ${ }^{a}$ & $37 \%$ & & $40 \%$ & & & \\
\hline \multicolumn{7}{|l|}{ Life situation } \\
\hline With partner & $30 \%$ & & $30 \%$ & & & \\
\hline With partner and siblings & $3 \%$ & & $7 \%$ & & & \\
\hline Alone & $43 \%$ & & $40 \%$ & & & \\
\hline Alone with siblings & $10 \%$ & & $10 \%$ & & & \\
\hline With parents & $7 \%$ & & $13 \%$ & & & \\
\hline Institution & $7 \%$ & & $0 \%$ & & & \\
\hline WAI & 63.04 & 13.96 & & & & \\
\hline GSI & 1.24 & 0.87 & 0.48 & 0.23 & 4.47 & 0.00 \\
\hline Mania (BRMS) & 3.10 & 2.94 & & & & \\
\hline Depression (MADRS) & 12.87 & 10.40 & & & & \\
\hline
\end{tabular}

BRMS, Bech-Rafaelson Mania Scale; MADRS, Montgomery \& Asberg Depression Rating Scale; GSI, General Symptom Index of Symptom Checklist SCL-90-R; WAI, Working Alliance Inventory.

${ }^{\text {a }}$ Considered as stable intimate relationship when lasting longer than 2 years.

such as drug abuse (23\%, cannabis, alcohol, cocaine), personality disorders cluster C (10\%), obsessive-compulsive disorders (3\%), acute suicidality (3\%) and epilepsy (3\%). Diagnoses were established by trained staff by means of the Structured Clinical Interview for DSM-IV (SCID; First et al. 2004; only the module on BD). The number of in-patient treatments in psychiatry, including current treatment, varied between 1 and 29 (mean =7.7, S.D. $=7.0$ ).

A strictly matched control group was introduced; matching criteria were gender, age and years of education, as these have an influence on cognitive functioning (Labouvie-Vief et al. 1987; Whitty, 2003). A total of 30 persons from a community sample were recruited for the study, of which $20(67 \%)$ were female; the controls had a mean age of 41.9 (S.D. $=14.3$, range 23-65). Their mean number of years of education was 12.9 (S.D. $=1.4$, range $11-$ 18), corresponding to intermediate education level in Switzerland. No in-patient psychiatric treatment was known for these participants and general symptomatology was in the normal range for all control participants. $t$ tests yielded no significant differences in the matching variables between the groups (see Table 1). All participants gave written consent.

\section{Instruments}

CE (Drapeau, et al. 2005; French translation by Kramer \& Drapeau, 2005). This is an observer-rating system assessing CE in interview transcripts (Drapeau, \& Perry, 2005). It assesses 14 different CE, based on J. Beck (1995) and A. T. Beck (1976): (1) Fortune-telling, (2) Labelling, (3) Overgeneralizing, (4) All-or-nothing, (5) Discounting the positive/negative, (6) Emotional reasoning, (7) Magnification/minimization of positive/negative, (8) Mental filter, (9) Should and must, (10) Tunnel vision, (11) Jumping to conclusions, (12) Mind-reading, 
(13) Personalization, (14) Inappropriate blaming of self. All errors are broken down according to their valence: positive and negative. According to Lefebvre (1981), they can be classified in four higher-order categories: fortune-telling (error 1); overgeneralizing (errors 2 and 3); selective abstraction (errors 4-11); personalization (errors 12-14). According to Henriques \& Leitenberg (2002), an overall ratio can be computed by dividing the proportion of negative $\mathrm{CE}$ by the proportion of positive CE. For all computations, relative frequencies are used, by weighting the absolute frequency of each error by the number of words uttered by the patient (excluding therapist interventions and patient's hesitations) yielding a score for each error per 1000 words. Preliminary empirical validation data have been presented in several studies, accounting for sufficient internal and external validity (see Drapeau \& Perry, 2005; D'Iuso et al. 2007; Drapeau et al. 2007; Perry et al. 2007 for the original English version), and Kramer (2006) and Kramer \& Drapeau (in press) for the French version used for our study). For the current study, reliability coefficients on $20 \%$ of the ratings were established among fully trained raters and yielded satisfactory results in terms of intra-class correlation coefficients (ICC) (2, 1; Wirtz \& Caspar, 2002) varying between 0.48 and 0.95 (mean $=0.80$, S.D. $=0.12$, the 0.48 ICC value being an exception for a particular difficult rating on a patient presenting with psychotic symptoms, the next lowest value in this distribution was 0.62 ). These coefficients were established on single errors broken down into positive and negative valence as unit of analysis (28 categories). ICC $(2,1)$ with the CE authors' group of raters varied between 0.51 and 0.83 (mean $=0.71$, S.D. $=0.11$; the 0.51 rating is the only one $<0.60$ ).

Symptom Check List SCL-90-R (Derogatis, 1994). This questionnaire includes 90 items addressing various somatic and psychological signs of distress. These items are scored using a Likert-type scale from 0 (not at all) to 4 (very much). Although the instrument is composed of 10 subscales, our study used only the General Symptomatic Index (GSI, score ranging from 0 to 4 ), which is a mean rated over all symptoms. The clinical cut-off score is 0.80 . The French validation study was carried out by Pariente \& Guelfi (1990) and yielded satisfactory coefficients. Cronbach's alpha for this sample was 0.98. Mean symptom level for patients was higher than for controls (see Table 1; range of our patients' scores: 0.12-3.17).

Bech-Rafaelson Mania Scale (BRMS; Bech et al. 1978). The BRMS is a clinician-rated scale for manic symptoms, based on 11 items tapping activity level, mood, and other characteristics of mania. The items are rated on a scale from 0 (normal) to 4 (extreme). The clinical cut-off score for mania is 15 (hypomania 6). The range of our patients' scores was 0-12. Inter-rater reliability proved to be high (0.80-0.95; Bech et al. 1978; Altman, 2004). BPRS is effective in assessing outcome in clinical trials on BD (Bech, 2002). The French translation was validated by Chambon et al. (1989). Cronbach's alpha for our patient sample was 0.77 .

Montgomery-Asberg Depression Rating Scale (MADRS; Montgomery \& Asberg, 1979). MADRS is a clinician-rated scale for depressive symptoms, including among others items on sadness, internal tensions, insomnia, appetite reduction, cognitive impairment and suicidal ideation. The 10 items are anchored on a scale from 0 (absence of symptoms) to 6 (maximal level of symptoms). The clinical cut-off score for depression is 15 . The range of our patients' scores was $0-38$. Several validation studies reported satisfactory coefficients for the original version (Montgomery, \& Asberg, 1979) and concurrent validity (Kearns et al. 1982; Maier \& Philipp, 1985). The French translation was validated by Lemperière et al. (1984) and validation 
studies on this version yielded satisfactory coefficients on specificity, homogeneity and internal consistency (Pellet et al. 1987). Cronbach's alpha for our patient sample was 0.89 .

Working Alliance Inventory (WAI; Horvath, 1981; Horvath \& Greenberg, 1989). The WAI was originally a 36-item self-report measure assessing the quality of the therapeutic alliance according Bordin's conception (1975). Responses are reported on a 7-point Likert-type scale ranging from 1 (never) to 7 (always). Construct validity was established by Malinckrodt \& Nelson, 1991), reliability for the whole scale ranged between 0.84 and 0.93 (Horvath, 1994). Concurrent and predictive validity was established (Tichenor \& Hill, 1989; Shick Tryon \& Kane, 1993). A 12-item short version was developed by Tracey \& Kokotovic (1989), based on factor-analytical procedures. Its French translation was validated by Corbière et al. (2006) who suggested one general score be considered for the evaluation of alliance. The short version was used for our study. Cronbach's alpha for this patient sample was 0.87 .

\section{Procedure}

All patients and controls were asked to participate in a dynamic interview (DI; Perry et al. 2005) lasting 50 minutes. DI as a research tool has been developed from clinical practice of psychodynamic psychotherapy; thus, the context of DI is comparable to the context of an intake psychotherapy interview (J. C. Perry, personal communication). It has been widely used in psychotherapy research (Perry \& Cooper, 1989; Hoglend \& Perry, 1998). As shown by Perry et al. (2005) and Fowler \& Perry (2005), high-quality dynamic interviews are associated with five tasks of the interviewer: (1) setting the interview frame: work-enhancing strategies; (2) offering support: questions, support strategies, associations; (3) exploration of affect: questions, reflections, clarifications, low-level defence interpretations; (4) trial interpretations: defence and transference interpretations; (5) offering a synthesis.

In particular, exploring affect and trial interpretations are highly correlated with overall dynamic interview adequacy (O-DIA), when the patient's contribution is controlled for (Perry et al. 2005). The first author completed an intensive 1 week's training at Austen Riggs Center, Stockbridge, USA, and later underwent regular supervision with senior supervisors in psychodynamic psychotherapy. All interviews were conducted in French by the first author. We believe that the specific tasks required from the therapist during a DI are similar to the tasks in any psychotherapy intake interview; moreover, the interviewer is a psychotherapist with full cognitive-behaviooral training; therefore, we assume this interview technique has a high external validity across therapy approaches.

All in-patients participated in the DI, as soon as their symptomatic state allowed. This means that the patients were included just prior to discharge from in-patient treatment. Only two patients had to be excluded from the study due to non-feasibility of the research interview; all other patients responding to the inclusion criteria and willing to participate were included. The patients were given treatment as usual, encompassing non-specific supportive therapy and medication according to the guidelines published by the World Federation of Society of Biological Psychiatry (Grunze et al. 2002). Along with the DI, the evaluation procedure encompassed clinician ratings of depression and mania. The patients were given the questionnaires at the end of the interview and were asked to complete and return them within 2 days. The study was endorsed by the expert ethical committee of the psychiatric hospital.

The control group was recruited by means of two local institutions: (1) School of Social Studies $(n=17)$; (2) 'Femmes solidaires' - an association promoting community activities 
and service $(n=13)$. Matching criteria were transparently issued at the outset of the control group recruitment. Therefore, only nine participants were excluded from participation due to failure to meet the matching criteria. The control participants, unlike the patients who were not paid, received a contribution (the equivalent of US\$16). The study was endorsed by the expert ethical committee of the School of Social Studies.

All interviews were tape-recorded and transcribed by Master's-level psychology students, according to the method defined by Mergenthaler \& Stigler (1997). Interviews were rated based on these transcripts. CE ratings were performed by fully trained raters, including the first author. Four Master's-level psychology students were trained during 4 months by the first author and reliability was established on a dyadic basis among the student raters, between the student raters and the trainer and between the student raters and the authors of the CE method. A randomly chosen $20 \%$ of all interviews were rated by two raters independently in order to establish inter-rater reliability checks (for results see Instruments section above).

\section{Data analytical strategy}

We performed ANOVA and MANOVA statistical analyses in order to answer the first two hypotheses regarding the heightened level of $\mathrm{CE}$ in $\mathrm{BD}$ : (1) compared to controls and (2) comparing the two BD subgroups with each other. For both hypotheses, univariate testing was used for number of words, number of $\mathrm{CE}$ and the negative-to-positive ratio. For the first hypothesis, patients were compared to controls, for the second, two subgroups of patients were compared with each other. These subgroups were obtained by median-split method of the ratio BRMS/MADRS (in order to be able to perform the variable transformation for all 30 cases, the MADRS score was transformed by adding 1 to the initial score, thus preventing the exclusion of two cases with a score of 0 on MADRS). We applied multivariate statistics to the four categories per error valence. In order to test hypotheses 3 and 4 on the links between the $\mathrm{CE}$ and (3) the level of symptoms and (4) the therapeutic alliance, zero-order Pearson's correlations were performed. We applied Bonferroni's correction as necessary.

\section{Results}

\section{Preliminary analyses}

The total number of words was constantly higher for controls, compared to patients. For the first interview, patients had a mean of 5955 words (S.D. $=1903$ ), controls 7810 words [S.D. $=$ $2514, F(1,59)=10.61, p=0.00]$. Comparing the depression subgroup to the mania subgroup (both $n=15$ ), the mania subgroup produced more words $($ mean $=6835$, S.D. $=1903)$ than the depression subgroup [mean $=5037$, S.D. $=1207, F(1,29)=8.38, p=0.01]$.

\section{CE in BD patients vs. controls}

After controlling for the number of words produced, only one between-group effect remained significant: patients overall made more errors of any type than controls $(p<0.05)$. No effect was found with regard to the specific categories, nor the negative-to-positive valence ratio (see Table 2). 
Table 2. Cognitive errors/1000 words in bipolar affective disorder

\begin{tabular}{|c|c|c|c|c|c|c|}
\hline \multirow[b]{2}{*}{ Errors } & \multicolumn{2}{|c|}{ Patients $(n=30)$} & \multicolumn{2}{|c|}{ Controls $(n=30)$} & \multirow[b]{2}{*}{$F(1,59)$} & \multirow{2}{*}{$\begin{array}{l}\text { Effec } \\
\text { size }\end{array}$} \\
\hline & Mean & S.D. & Mean & S.D. & & \\
\hline Number of errors & 15.87 & 6.60 & 12.50 & 4.88 & $5.04^{*}$ & 0.58 \\
\hline Ratio (neg./pos.) & 2.53 & 2.82 & 1.77 & 1.51 & 1.55 & 0.34 \\
\hline \multicolumn{7}{|l|}{ Positive errors } \\
\hline Fortune-telling & 0.17 & 0.46 & 0.27 & 0.58 & 0.54 & 0.19 \\
\hline Overgeneralizing & 5.54 & 7.43 & 8.45 & 8.67 & 1.95 & 0.36 \\
\hline Selective abstraction & 36.87 & 44.34 & 28.48 & 24.18 & 0.83 & 0.24 \\
\hline Personalization & 1.02 & 2.75 & 0.53 & 2.05 & 0.62 & 0.20 \\
\hline \multicolumn{7}{|l|}{ Negative errors } \\
\hline Fortune-telling & 0.60 & 0.89 & 0.33 & 0.61 & 1.83 & 0.35 \\
\hline Overgeneralizing & 13.90 & 11.49 & 13.72 & 11.64 & 0.00 & 0.02 \\
\hline Selective abstraction & 35.61 & 17.38 & 27.79 & 31.22 & 1.44 & 0.31 \\
\hline Personalization & 5.60 & 8.03 & 5.39 & 7.42 & 0.01 & 0.03 \\
\hline
\end{tabular}

MANOVA: Positive errors: $F(4,55)=1.44, p=0.23$; negative errors: $F(4,55)=0.85, p=0.50$; Bonferroni's correction applied.

${ }^{*} p<0.05$.

\section{CE in BD patients: mania vs. depression}

When dividing the patient group according to the predominant symptomatology, mania or depression, it appeared that the negative-to-positive valence ratio was highly significant: BD patients with depressive symptoms had a higher ratio, compared to BD patients with manic symptoms. Moreover, in line with this first result, patients with manic symptoms displayed more positive errors compared to patients with depressive symptoms; in particular, the category of selective abstraction, e.g. emotional reasoning, jumping to conclusions, magnification of the positive, was different between the two subgroups. However, no difference was found in negative errors (see Table 3). There were no between-subgroup differences as regards sociodemographic variables [gender: $\chi^{2}(1 ; n=15)=3.33$, n.s.; age: $t(1,28)=-1.11$, n.s.; level of education: $t(1,28)=0.17$, n.s.].

\section{CE and level of symptoms}

Pearson correlational analyses yielded a clear picture for manic symptoms that were related to the level of positive errors $(r=0.57, p=0.00)$. Depressive symptoms were inversely related to positive errors $(r=-0.53, p=0.00$ ), but not to negative ones (see Table 4 ). Due to the relative small sample size, these analyses are exploratory.

\section{CE and therapeutic alliance}

We performed a Pearson correlation between WAI and the CE positive and negative scores; the total number of observations was lower due to missing values $(n=24)$. A significant negative correlation existed between positive $\mathrm{CE}$ and the therapeutic alliance measured by WAI 
Table 3. Cognitive errors/1000 words as a function of symptomatic subsamples

\begin{tabular}{|c|c|c|c|c|c|c|}
\hline \multirow[b]{2}{*}{ Errors } & \multicolumn{2}{|c|}{ Depression $(n=15)$} & \multicolumn{2}{|c|}{ Mania $(n=15)$} & \multirow[b]{2}{*}{$F(1,29)$} & \multirow{2}{*}{$\begin{array}{l}\text { Effec } \\
\text { size }\end{array}$} \\
\hline & Mean & S.D. & Mean & S.D. & & \\
\hline Number of errors & 14.93 & 5.64 & 16.80 & 7.52 & 0.59 & 0.28 \\
\hline Ratio (neg./pos.) & 4.04 & 3.43 & 1.12 & 0.74 & $10.37^{* *}$ & 1.18 \\
\hline \multicolumn{7}{|l|}{ Positive errors } \\
\hline Fortune-telling & 0.07 & 0.26 & 0.27 & 0.59 & 0.89 & 0.44 \\
\hline Overgeneralizing & 4.25 & 8.53 & 6.82 & 6.17 & 0.89 & 0.35 \\
\hline Selective abstraction & 15.56 & 12.30 & 58.18 & 54.30 & $8.79^{* *}$ & 1.08 \\
\hline Personalization & 0.97 & 2.71 & 1.07 & 2.89 & 0.01 & 0.04 \\
\hline \multicolumn{7}{|l|}{ Negative errors } \\
\hline Fortune-telling & 0.73 & 1.10 & 0.47 & 0.64 & 0.66 & 0.29 \\
\hline Overgeneralizing & 12.37 & 11.42 & 15.07 & 11.80 & 0.41 & 0.23 \\
\hline Selective abstraction & 28.93 & 10.70 & 26.66 & 22.55 & 0.12 & 0.13 \\
\hline Personalization & 6.35 & 6.71 & 4.43 & 9.30 & 0.42 & 0.24 \\
\hline
\end{tabular}

MANOVA: Positive errors: $F(4,25)=2.29, p=0.05$; negative errors: $F(4,25)=0.43, p=0.78$; Bonferroni's correction applied (significance level $0.01 / 2$ or $0.05 / 2$ ).

${ }^{* *} p<0.01$.

Table 4. Pearson's correlations between manic/depressive symptoms and cognitive errors $(n=30)$

\begin{tabular}{lll}
\hline & \multicolumn{2}{l}{ Cognitive errors } \\
\cline { 2 - 3 } Variable & Positive & Negative \\
\hline Bech-Rafaelson Mania Scale & $0.57^{* *}$ & 0.22 \\
Montgomery-Asberg Depression & $-0.53^{* *}$ & 0.07 \\
$\quad$ Rating Scale & & \\
\hline${ }^{* *} p<0.01$. & &
\end{tabular}

( $r=-0.50, p=0.01$ ), whereas no relationship was found between negative CE and WAI $(r=-0.24, p=0.26)$.

\section{Discussion}

Our hypotheses were generally confirmed by the results. By testing a first sub-version of the universality hypothesis, we have shown that BD patients display overall more $\mathrm{CE}$ in their spontaneous in-session narrative than matched controls. However, no effect was found per error valence between the groups. These results indicate that the symptoms related to the BD diagnosis suffice for detection of an overall heightened level of CE, but not for the detection of differences in specific categories (Clark et al. 1999); potential effects are probably neutralized in such between-group comparisons by partially exclusive symptom patterns. The latter are particularly decisive in BD patients, as mania and depression fluctuate highly, sometimes rapidly; in consequence, these state-dependent parameters need to be entered as separate analyses. When comparing the two symptomatic subgroups with each other, the effect 
of overall frequency of errors disappears, but the negative-to-positive valence ratio yields an effect which tends to confirm, again, the universality hypothesis for bipolar depression (Henriques \& Leitenberg, 2002; see also Clark et al. 1999). Selective abstraction positivity is more frequent in manic patients, but no between-subgroup difference was found for negative $\mathrm{CE}$, due to a relatively high level of negative CE in mania. Correlational analyses confirm that manic symptoms in BD patients are not only characterized or maintained by heightened positive thinking (i.e. selective abstraction), but also by heightened negative thinking (i.e. overgeneralizing). These results also tend to confirm Beck's exclusivity hypothesis for BD (Clark et al. 1999) stating that depression is characterized by the absence of positive selfreferent thinking. However, the absence of effect related to negative $\mathrm{CE}$ in the depressive phase - due to heightened negative CE in mania rendering this likely effect insignificant questions the generalizability to BD of Beck's negativity hypothesis. Biases towards particularly negative information processing and content are widely confirmed for unipolar depression, but negativity in depressive states in BD patients is not heightened when compared to manic or hypomanic states, and also when compared to matched controls. These heightened levels of negative errors in manic states might be due to persistence of negativity across BD phases, representing a vulnerability factor for relapse into depression (see also comparable results found by Goldberg et al. 2008 in a questionnaire-study and by Weintraub et al. 1974 on unipolar depression). As predicted by Mansell et al.'s (2007) model, negativity may be present as part of extreme conflicting cognition (positive $v s$. negative) in particular in mania. This recent cognitive model enables differentiation of cognitive biases with regard to their content: in particular, errors in interpretation of the internal physical state may be analysed, as opposed to $\mathrm{CE}$ on any content (i.e. world, relationships, personal history) and related to current symptoms, e.g. the presence of ascent and descent behaviours (Mansell et al. 2007). The clinical method applied in our study may prove particularly useful for the validation of this model assumption.

With regard to the therapeutic alliance, we were able to partially confirm our hypothesis. Only positive CE are inversely related to the level of therapeutic alliance, no relationship was found for positive errors. This result, based on exploratory analyses, may suggest a limiting role of heightened levels of CE in the development of a therapeutic alliance with the patient.

There are at least two clinical implications ensuing from the present study. First, clinicians should be aware of the occurrence of cognitive biases in their BD patients, since higher levels of symptoms are related to some types of cognitive biases. While the observation in manic and hypomanic patients of their discounting negative information is probably a truism for clinicians, the underlying presence, in the same patients, of a set of negative CE also related to mania, may be counter-intuitive. Therefore, this should be emphasized in the training of cognitive psychotherapists, to avoid them remaining in their own possible positively valenced $\mathrm{CE}$, i.e. discounting the negative information. The second implication is the clinician's awareness of selective abstraction as a possible hindrance in the construction of a positive therapeutic alliance. Even if BD patients show many positive selective abstraction errors, possibly also with regard to the therapeutic relationship, the clinician needs to address them systematically, i.e. by means of Socratic dialogue. It goes without saying that this procedure does not imply replacing positivity by negativity (or vice versa), but it implies the collaborative therapeutic negotiation of a nuanced and adaptive view of the self and the self-in-interaction (Clark et al. 1999). 
To summarize, BD patients display a higher frequency of CE than controls. Manic symptoms are associated with more positive $\mathrm{CE}$, as well as negative $\mathrm{CE}$, thus adding an argument for corroboration of Beck's universality and exclusivity hypotheses. No effect was found for negative $\mathrm{CE}$ in bipolar depression.

There are several limitations to this study. Comorbidity in the patient sample somewhat limits internal validity of the trial, but enhances external validity. It should be acknowledged that no patient presented full manic symptoms according to the clinical cut-off, thus confining the relevance of our results to patients in submanic or hypomanic states; caution with generalizations to fully manic states needs to be applied. Finally, participants in the control group were not randomly chosen, due to matching criteria and the voluntary status of participation and thus, their error profiles are not representative of the general population; caution with generalizations should be exercised.

\section{Acknowledgements}

The authors thank Daniela Dremmel, Natalia Pasandin, Isabel Reboh and Nicolas Zufferey for their work of transcription and rating. No specific funding was necessary to conduct the study.

\section{Declaration of Interest}

None.

\section{References}

Altman E (2004). Differential diagnosis and assessment of adult bipolar disorder. In: Psychological Treatment of Bipolar Disorder (ed. S. L. Johnson and R. L. Leahy), pp. 35-57. New York: The Guilford Press.

Bech P (2002). The Bech-Rafaelson Mania Scale in clinical trials of therapies for bipolar disorder: A 20-year review of its use as an outcome measure. CNS Drugs 16, 47-63.

Bech P, Rafaelson OJ, Kramp P, Bolweg TG (1978). The mania rating scale: scale construction and inter-observer agreement. Neuropharmacology 17, 430-431.

Beck AT (1963). Thinking and depression. 1. Idiosyncratic content and cognitive distortions. Archives of General Psychiatry 9, 324-333.

Beck AT (1967). Depression: Causes and Treatment. Philadelphia: University of Pennsylvania Press.

Beck AT (1976). Cognitive Therapy and the Emotional Disorders. New York: International Universities Press.

Beck AT (1991). Cognitive therapy. A 30-year perspective. American Psychologist 46, 368-375.

Beck JS (1995). Cognitive Therapy. Basics and Beyond. New York: Guilford Press.

Bordin ES (1975). The working alliance: basis for a general theory of psychotherapy. Paper presented at the Meeting of the Society for Psychotherapy Research, Washington, D.C., 1975.

Chambon O, Poncet F, Kiss L (1989). Echelles d'anxiété, de manie, de dépression, de schizophrénie [Scales for Assessment of Anxiety, Mania, Depression, Schizophrenia]. Paris: Masson.

Clark DA, Beck AT, Alford BA (1999). Scientific Foundations of Cognitive Theory and Therapy of Depression. New York: John Wiley \& Sons.

Corbière M, Bisson J, Lauzon S, Richard N (2006). Factorial validation of a French short-form of the Working Alliance Inventory. International Journal of Methods in Psychiatric Research 15, $36-45$. 
Derogatis LR (1994). Symptom Checklist-90 - Revised: Administration Scoring and Procedures Manual, 3rd edn. Minneapolis, MN: National Computers Systems.

D'Iuso D, Blake E, Drapeau M (2007). An investigation of the relationship of Cognitive Errors and Coping Action Patterns with the Therapeutic Alliance. Canadian Psychological Association Annual Convention. Ottawa, 2007.

Drapeau M, Perry JC (2005). Observer ratings of coping and cognitive errors: the Cognitive Errors and Coping Action Patterns (CECAP) method. Paper presented at the Annual Meeting of the Society for Psychotherapy Research. Montreal, 2005.

Drapeau M, Perry JC, Blake E, D'Iuso D (2007). A pilot study of the validity and reliability of the CECAP method. Canadian Psychological Association Annual Convention. Ottawa, 2007.

Drapeau M, Perry JC, Dunkley D (2005). The Cognitive Errors Rating System. McGill University.

Eells T, Fridhandler Stinson CH, Horowitz MJ (1993). Commentary to self-representation in posttraumatic stress disorder: a cognitive perspective. In: The Self in Emotional Distress. Cognitive and Psychodynamic Perspectives (ed. Z. V. Segal and S. J. Blatt), pp. 92-99. New York: Guilford Press.

Eich E, Macaulay D, Lam RW (1997). Mania, depression, and mood dependent memory. Cognition and Emotion 11, 607-618.

First MB, Spitzer RL, Williams JBW, Gibbons M (2004). Structured Clinical Interview for DSM-IV. New York: Biometrics Research Department.

Fowler JC, Perry JC (2005). Clinical tasks of the dynamic interview. Psychiatry: Interpersonal and Biological Processes 68, 316-336.

Goldberg JF, Gerstein RK, Wenze SJ, Welker TM, Beck AT (2008). Dysfunctional attitudes and cognitive schemas in bipolar manic and unipolar depressed outpatients. implications for cognitively based psychotherapeutics. Journal of Nervous and Mental Disease 196, 207-210.

Greenhouse WJ, Meyer B, Johnson SL (2000). Coping and medication adherence in Bipolar Disorder, Journal of Affective Disorders 59, 237-241.

Grunze H, Kasper S, Goodwin G, Bowden CL, Baldwin D, Licht RW, Vieta E, Möller H-J (2002). The World Federation of Society of Biological Psychiatry (WFSBP). Guidelines for the biological treatment of bipolar disorders. I-III. World Journal of Biological Psychiatry 3, 115-124.

Haaga DAF, Dyck MJ, Ernst D (1991). Empirical status of cognitive theory of depression. Psychological Bulletin 110, 215-236.

Hammen CL (1978). Depression, distortion, and life stress in college students. Cognitive Therapy and Research 2, 189-192.

Hammen CL, Krantz S (1976). Effects of success and failure on depressive cognitions. Journal of Abnormal Psychology 85, 577-586.

Henriques G, Leitenberg $\mathbf{H}$ (2002). An experimental analysis of the role of cognitive errors in the development of depressed mood following negative social feedback. Cognitive Therapy and Research 26, 245-260.

Hoglend P, Perry JC (1998). Defensive functioning predicts improvement in major depressive episodes. Journal of Nervous and Mental Disease 186, 1-7.

Horvath AO (1981). An exploratory study of the working alliance: its measurement and relationship to therapy outcome. Unpublished doctoral dissertation. University of British Columbia, Canada.

Horvath AO (1994). Empirical validation of Bordin's pantheoretical model of the alliance: The Working Alliance Inventory perspective. In: The Working Alliance: Theory, Research, and Practice (ed. A. O. Horvath and L. S. Greenberg), pp. 109-130. New York: John Wiley.

Horvath AO, Greenberg LS (1989). The development and validation of the Working Alliance Inventory. Journal of Counseling Psychology 36, 223-233.

Jermann F, Van der Linden M, Adam S, Ceschi G, Perroud A (2005). Controlled and automatic uses of memory in depressed patients: effects of retention interval lengths. Behaviour Research and Therapy 43, 681-690. 
Johnson SL, Carver CS (2006). Extreme goal setting and vulnerability to mania among undiagnosed young adults. Cognitive Therapy and Research 30, 377-395.

Jones S, Mansell W, Waller L (2006). Appraisal of hypomania-relevant experiences: Development of a questionnaire to assess positive self-dispositional appraisals in bipolar and behavioural high risk samples. Journal of Affective Disorders 93, 19-28.

Kearns NP, Cruickshank CA, McGuigan KJ, Riley SA, Shaw SP, Snaith RP (1982). A comparison of depression rating scales. British Journal of Psychiatry 141, 45-49.

Kramer U (2006). Cognitive errors and coping action patterns: new strategies of conceptualization. Poster presented at the 13th Herbstakademie, Ascona, Switzerland, 5-8 October 2006.

Kramer U, Drapeau M (in press). Validation studies of the French Version of the Rating Scales on Coping and Cognitive Errors (CE-CAP) on a non-clinical population [in French]. Annales MédicoPsychologiques.

Kramer U, Drapeau M, Khazaal Y, Bodenmann G (in press). Coping specificities in bipolar affective disorder: relations with symptoms and therapeutic alliance. German Journal of Psychiatry.

Krantz S, Hammen C (1979). Assessment of cognitive bias in depression. Journal of Abnormal Psychology 88, 611-619.

Labouvie-Vief G, Hakim-Larson J, Hobart CJ (1987). Age, ego level, and the life-span development of coping and defense processes. Psychology and Aging 2, 286-293.

Lam DH, Wong G, Sham P (2001). Prodromes, coping strategies and course of illness in bipolar affective disorders - a naturalistic study. Psychological Medicine 31, 1397-1402.

Lam DH, Wright K, Smith N (2004). Dysfunctional attitudes: extreme goal-attainment beliefs in remitted bipolar patients. Journal of Affective Disorders 79, 193-199.

Leahy RL (2003). Cognitive Therapy Techniques: A Practitioner's Guide. New York: Guilford Press.

Lefebvre MF (1981). Cognitive distortion and cognitive errors in depressed psychiatric and low back pain patients. Journal of Consulting and Clinical Psychology 49, 517-525.

Lemperière T, Lepine JP, Rouillon F, Hardy P, Ades J, Luauté JP, Ferrand I (1984). Comparison between different assessment instruments of depression in the study of Athymil $30 \mathrm{mg}$ [in French]. Annales Médico-Psychologiques 142, 1206-1212.

Maier W, Philipp M (1985). Comparative analysis of observer depression scales. Acta Psychiatrica Scandinavica 72, 239-245.

Malinckrodt B, Nelson ML (1991). Counselor training level and the formation of the psychotherapeutic working alliance. Journal of Counseling Psychology 38, 133-138.

Mansell W, Jones SH (2006). The Brief-HAPPI: a questionnaire to assess cognitions that distinguish between individuals with a diagnosis of bipolar disorder and non-clinical controls. Journal of Affective Disorder 93, 29-34.

Mansell W, Morrison AP, Reid G, Lowens I, Tai S (2007). The interpretation of, and response to, changes in internal states: An integrative cognitive model of mood swings and bipolar disorders. Behavioural and Cognitive Psychotherapy 35, 515-539.

Mergenthaler E, Stigler M (1997). Transribing rules for psychotherapy research (French adaptation) [in French]. Psychothérapies 17, 97-103.

Montgomery SA, Asberg M (1979). A new depression scale designed to be sensitive to change. British Journal of Psychiatry 134, 382-389.

Newman CF, Leahy RL, Beck AT, Reilly-Harrington Gyulai L (2001). Bipolar Disorder: A Cognitive Therapy Approach. Washington, D.C.: American Psychological Association.

Pariente P, Guelfi JD (1990). Self-report inventories of adult psychopathology, part 1: multidimensional inventories [in French]. Psychiatrie Psychobiologique 5, 49-63.

Pellet J, Decrat M, Lang F, Chazot L, Tatu P, Blanchon Y, Berlier JM (1987). Description of a sample of 300 MADRS scales on depressed subjects [in French]. Annales Médico-Psychologiques 145, 170-175. 
Perry JC, Cooper SH (1989). An empirical study of defense mechanisms I: Clinical Interview and life vignette ratings. Archives of General Psychiatry 46, 444-452.

Perry JC, Drapeau M, Dunkley D, Foley E, Blake E, Banon E (2007). Changes in cognitive errors and coping action patterns following 20 sessions of either dynamic psychotherapy or CBT for acute recurrent depression. Paper presented at the Annual Meeting of the Society for Psychotherapy Research. Madison, USA, 2007

Perry JC, Fowler JC, Semeniuk TT (2005). An investigation of tasks and techniques associated with dynamic interview adequacy. Journal of Nervous and Mental Disease 193, 136-139.

Peterson C, Seligman MEP (1984). Causal explanations as a risk factor for depression: theory and evidence. Psychological Review 91, 347-374.

Shick Tryon G, Kane AS (1993). Relationship of working alliance to mutual and unilateral termination. Journal of Counseling Psychology 40, 33-36.

Tichenor V, Hill CE (1989). Alliance. Psychotherapy 26, 195-199.

Tracey TJ, Kokotovic AM (1989). Factor structure of the Working Alliance Inventory. Psychological Assessment: A Journal of Consulting and Clinical Psychology 1, 207-210.

Weintraub M, Segal RM, Beck AT (1974). An investigation of cognition and affect in the depressive experiences of normal men. Journal of Consulting and Clinical Psychology 42, 911.

Weingartner H, Miller H, Murphy DL (1977). Mood-state-dependent retrieval of verbal associations. Journal of Abnormal Psychology 86, 276-284.

Whitty MT (2003). Coping and defending: age differences in maturity of defence mechanisms and coping strategies. Aging and Mental Health 7, 123-132.

Wirtz M, Caspar F (2002). Beurteilerübereinstimmung und Beurteilerreliabilität [Inter-rater Accordance and Inter-rater Reliability]. Göttingen: Hogrefe.

\section{Learning objectives}

(1) Cognitive errors (or cognitive biases) may be assessed reliably in clinical interview by means of observer-rater methodology.

(2) Patients with bipolar affective disorder use more cognitive errors in their spontaneous discourse than non-symptomatic controls.

(3) Manic symptoms not only relate to positive cognitive errors, but also to negative cognitive errors, which should be taken into account in CBT of bipolar affective disorder. 